\title{
PEMANFAATAN INTERNET OF THINGS PADA KENDALI LAMPU
}

\author{
Anggraini Kusumaningrum ${ }^{1}$, Asih Pujiastuti ${ }^{2}$, Muhammad Zeny $^{3}$ \\ Program Studi Teknik Informatika \\ Sekolah Tinggi Teknologi Adisutjipto Yogyakarta \\ anggraini@stta.ac.id ${ }^{1}$, asihpuji@stta.ac.id ${ }^{2}$, Muhzen@gmail.com ${ }^{3}$
}

\begin{abstract}
Lamp is a kind of electronic that created light. Light is obtained through the flow of electricity as a current to add a voltage. the die and the life of light are controled by humans using switch. Applying the Internet of Things, as known as IoT determined the life and the die of a lamp by determined by the active light censor. The die and the life of the lamp automatically depends on the light sensor by capturing the intensity of the light produced. The result of the function test found that the data in the form of lux value generated by the light sensor, the value is exposed on a website with the display of graphics and websites serve as a web service provides control values to determine the response lamp, if the value of lux above 30 percent then the lights off And vice versa if under 30 percent of the lamps are on, so that a small value will be sent to the lamp and the lamp will respond that the lights are off or on. So that humans only act as a watchdog and control of the value generated by the light sensor.
\end{abstract}

\section{Keywords : Lamp, Internet of Things, Sensor Light}

\section{Pendahuluan}

Internet merupakan dunia baru yang penuh pesona saat pertama kali muncul dan pertama kali dikenalkan, internet terus memikat untuk di ekplorasi lebih lanjut, digali dan di kembangkan oleh para ahli teknologi.

Seiring dengan semakin berkembangnya infrastruktur internet, bahkan bukan hanya smartphone dan komputer saja yang dapat terkoneksi dengan internet. Namun berbagai macam benda nyata akan terkoneksi dengan internet. Sebagai contoh dapat berupa peralatan elektronik, peralatan yang digunakan manusia, dan termasuk benda nyata apa saja yang semuanya tersambung ke jaringan lokal dan global melalui sensor yang tertanam dan selalu aktif. Di dunia bidang "IT", konsep ini telah dikenal dengan istilah "Internet of Things" atau yang disebut dengan singkatan IoT. Internet of Things (IoT) merupakan sebuah konsep yang bertujuan untuk memperluas manfaat dari konektivitas internet yang tersambung secara terus menerus. Internet of Things (IoT) mengacu pada benda yang diidentifikasi secara unik sebagai repservasi virtual dalam struktur berbasis internet. Internet of Things (IoT) sebagai sebuah infrastruktur jaringan global, yang menghubungkan benda-benda fisik dan virtual melalui eksploitasi data capture dan kemampuan komunikasi dengan sensor dan koneksi sebagai pengembangan layanan. Dalam hal tersebut dapat disimpulkan bahwa IoT mengacu dan memanfaatkan pada suatu benda yang nantinya benda tersebut akan dapat berkomunikasi antara satu dengan yang lain melalui sebuah jaringan internet. Salah satu dari penerapan IoT adalah pada kendali lampu.

\section{Landasan Teori}

Beberapa Penelitian yang telah dilakukan mengenai sistem ini adalah :

(Sutono, 2015) membuat perancangan sistem aplikasi otomatisasi lampu penerangan menggunakan sensor gerak dan sensor cahaya berbasis Arduino Uno. (Edikurniawan, 2013) membuat penerangan rumah otomatis dengan sensor cahaya berbasis mikrokontrol. (Erlina, 2013) membuat sistem pengendali ruangan secara otomatis menggunakan PC berbasis Mikrokontroler Arduino Uno. 
Penelitian - penelitian kajian pustaka diatas, menjadi acuan dalam pembuatan pengendali kendali lampu dengan menggunakan konsep IoT, dan landasan teori yang membahas tentang teori teori yang digunakan untuk mendukung pengerjaan proyek IoT pada kendali lampu, adalah sebagai berikut :

\subsection{Sensor Cahaya}

Sensor cahaya memberikan perubahan besaran elektrik pada saat terjadi perubahan intensitas cahaya yang diterima oleh sensor cahaya.

\subsection{Arduino Uno}

Arduino Uno merupakan papan sirkuit berbasis mikrokontroler ATmega328 dan sejumlah input/output (I/O) yang memudahkan pemakai untuk menciptakan berbagai proyek elektronika yang dikhususkan untuk menangani tujuan tertentu.

\section{3. $\quad$ Printed Circuit Board (PCB)}

PCB merupakan suatu papan yang berisi tentang komponen - komponen elektronika yang tersusun membentuk rangkaian elektronik atau tempat rangkaian elektronika yang menghubungkan komponen elektronik yang satu dengan lainnya tanpa menggunakan kabel.

\subsection{Wireless Esp 8266}

ESP8266 merupakan modul wifi yang berfungsi sebagai perangkat tambahan mikrokontroler seperti Arduino, agar dapat terhubung langsung dengan wifi dan membuat koneksi TCP/IP. Modul ini membutuhkan daya sekitar 3.3v dengan memiliki tiga mode wifi yaitu Station, access point dan Both.

\subsection{Access Point}

Access Point merupakan sebuah perangkat jaringan yang berisi sebuah transceiver dan antena untuk transmisi dan menerima sinyal ke dan dari clients remote. Dengan access point (AP) clients wireless bisa dengan cepat dan mudah untuk terhubung kepada jaringan LAN kabel secara wireless

\subsection{LCD $2 \times 16$}

LCD $2 \times 16$ merupakan jenis media tampilan, yang menampilkan teks, karakter angka dan simbol. LCD $2 \times 16$ sangat berfungsi sebagai penampil yang nantinya akan digunakan untuk menampilkan status kerja alat.

\subsection{Relay}

Relay merupakan komponen elektronika yang memiliki fungsi yang hampir sama dengan saklar/switch, komponen ini bekerja sebagai saklar mekanik yang digerakkan oleh energi listrik.

\section{$3 \quad$ Metode Penelitian}

\subsection{Skema Jaringan}

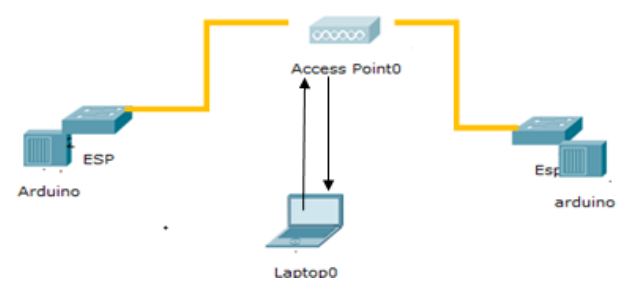

Gambar 1. Skema Jaringan 
Pada Gambar 1 menjelaskan tentang gambaran skema jaringan yang diterapkan pada kendali lampu dengan konsep IoT, yang menunjukan bahwa dari komponen satu dengan yang lain saling berkomunikasi dan interaksi satu sama lain, untuk menghasilkan suatu data yang dihasilkan sensor cahaya. Arduino sebelah kiri merupakan blok dari sensor cahaya sedengkan Arduino sebelah kiri merupakan blok pada Lampu LED dan laptop sebagai penampil grafik dari itensitas kecerahab cahaya.

\subsection{Cara Kerja Sistem Kendali Lampu Dengan Konsep IoT}

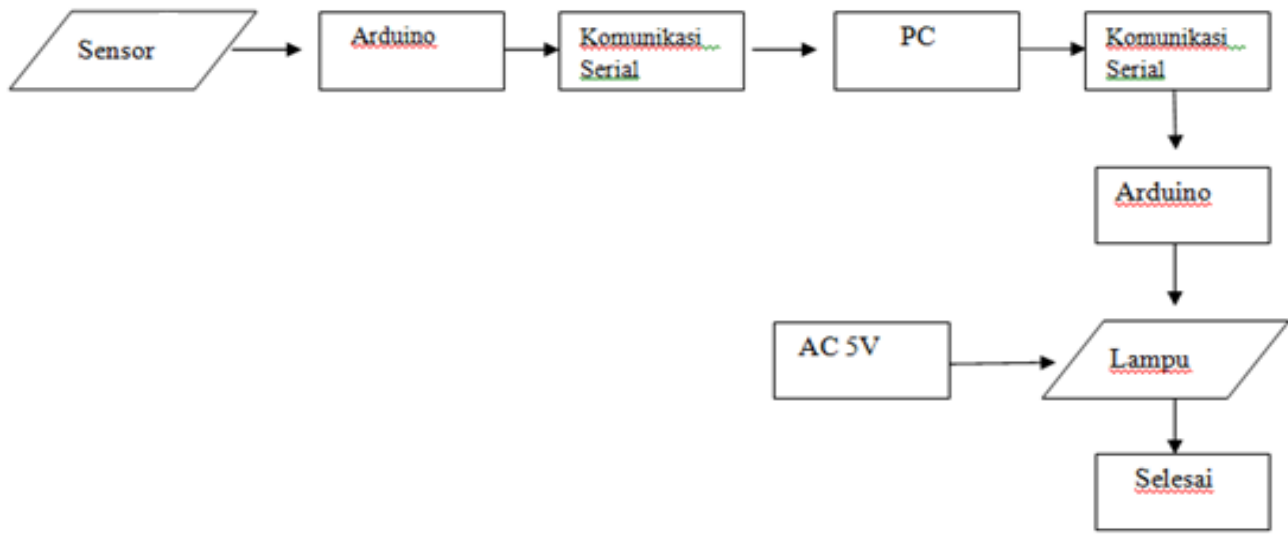

Gambar 2. Cara Kerja Sistem Kendali Lampu

Pada Gambar 2 menjelaskan tentang cara kerja kendali lampu, yang menunjukan setiap unit mempunyai perannya masing - masing dan saling terkoneksi satu sama lainnya.

\subsection{Cara Kerja Sistem Kendali Lampu Dengan Konsep IoT}

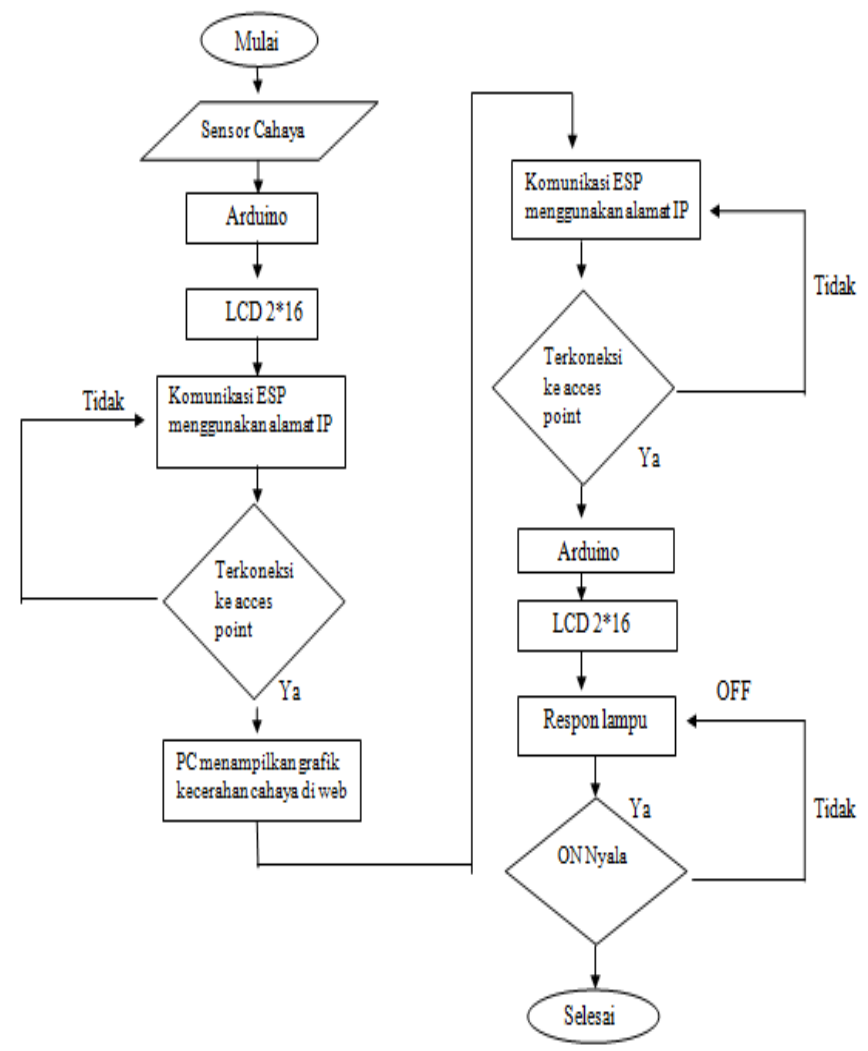

Gambar 3. Flowchart Sistem 
Pada Gambar 3 menjelaskan tentang flowchat sistem yang diterapkan pada kendali lampu dengan konsep IoT, menggambarkan bahwa sistem yang tersusun sesuai dengan kinerja dari kendali lampu.

\subsection{Perancangan Blok Sensor}

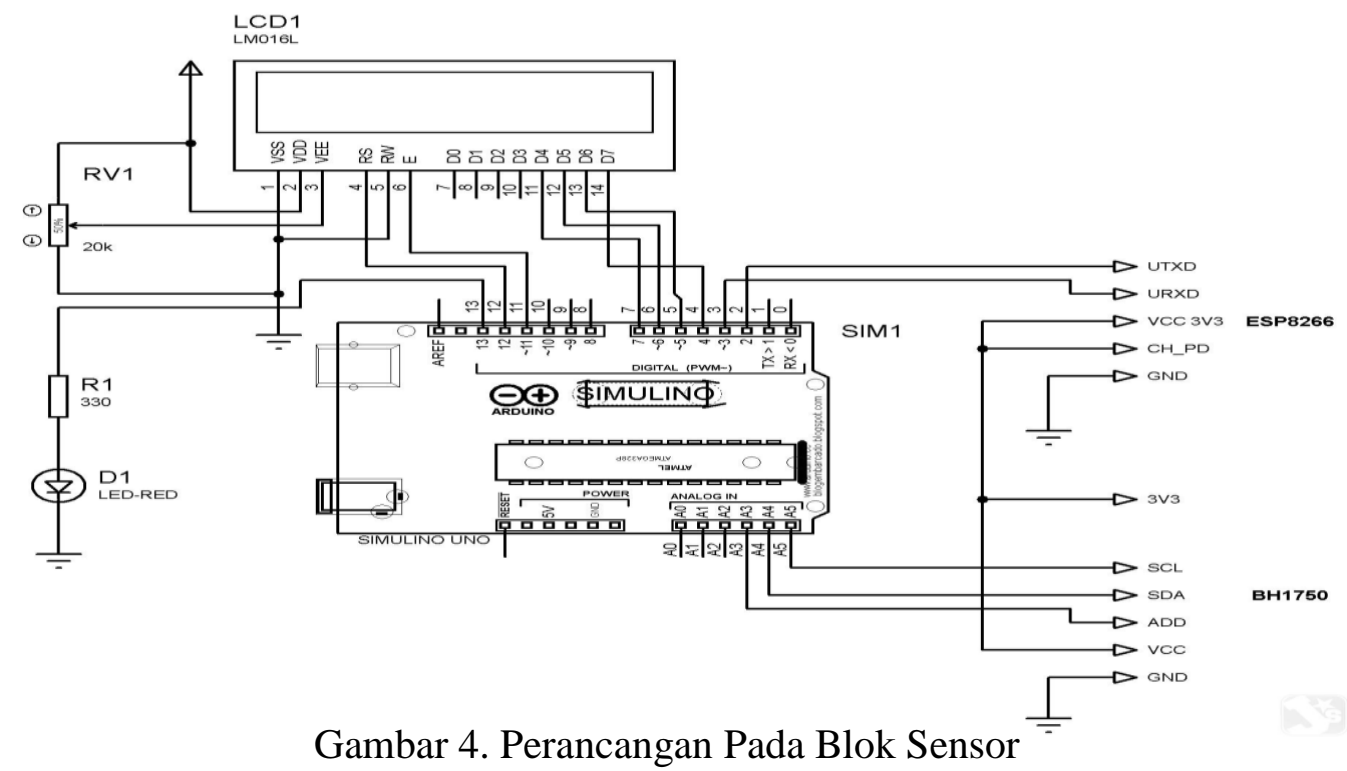

Pada Gambar 4 menjelaskan perancanagn pada blok lampu yang meliputi beberapa komponen diataranya adalah, Arduino Uno, Sensor cahaya, LCD 2×16, PCB dan Esp.

\subsection{Perancangan Pada Blok Lampu LED}

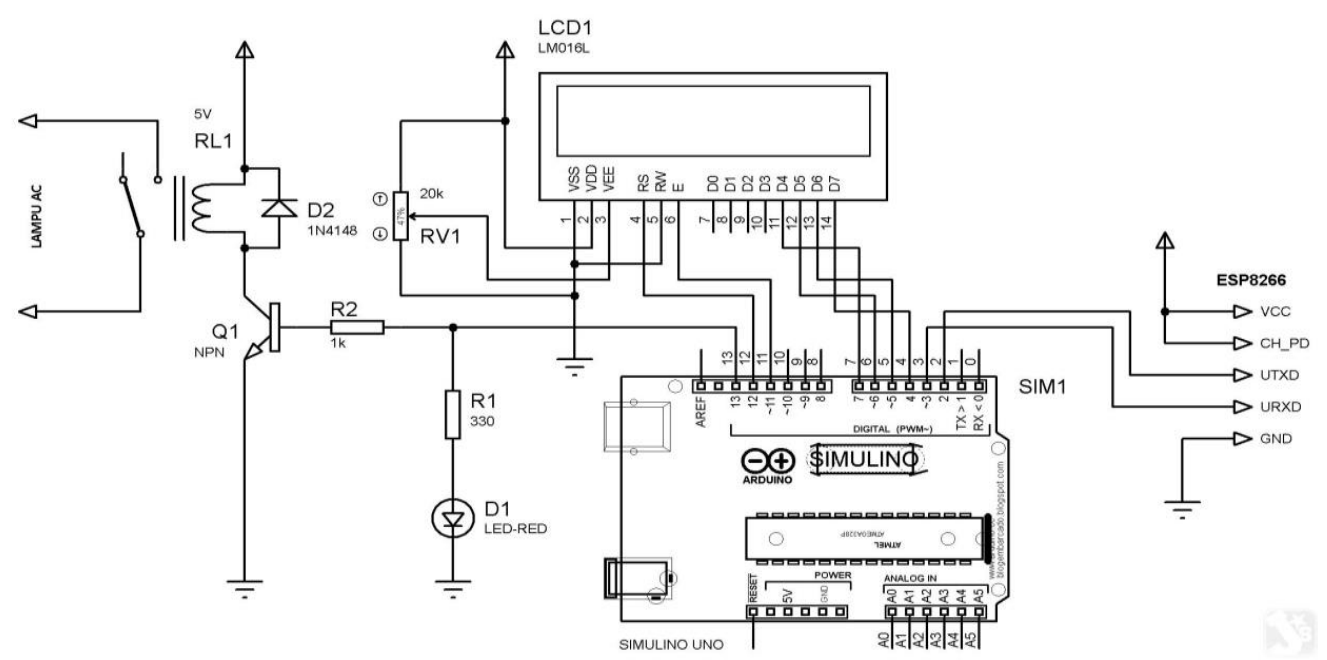

Gambar 5. Perancangan Pada Blok Lampu LED

Pada Gambar 5 menjelaskan perancangan pada blok lampu yang meliputi beberapa komponen diataranya adalah, Arduino Uno, Lampu LED, Relay, LCD 2×16, PCB dan Esp. 


\section{Hasil dan Pembahasan}

Tahap selanjutnya dari penelitian ini uji fungsi berupa pengujian pada kendali lampu dengan konsep IoT.

\subsection{Uji Fungsi Lampu OFF}

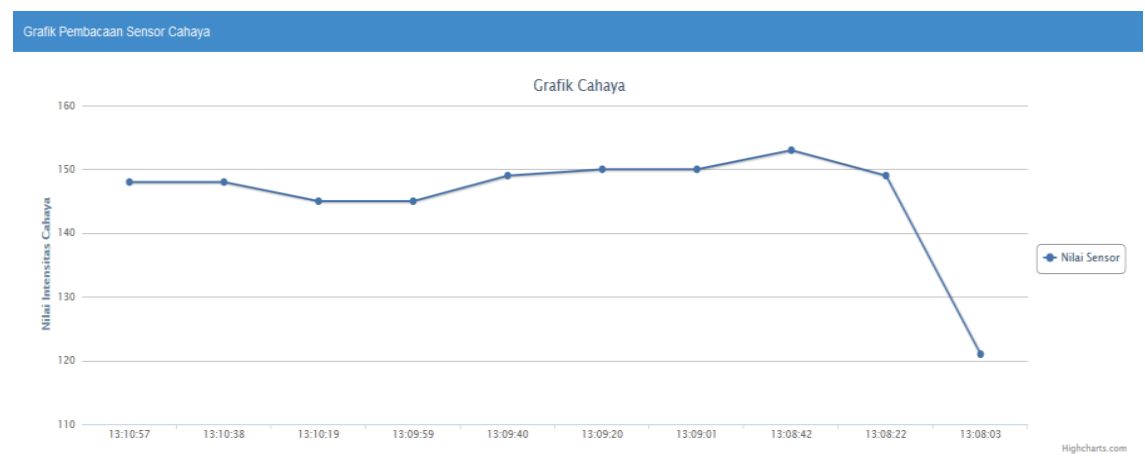

Gambar 6. Uji Fungsi Lampu OFF

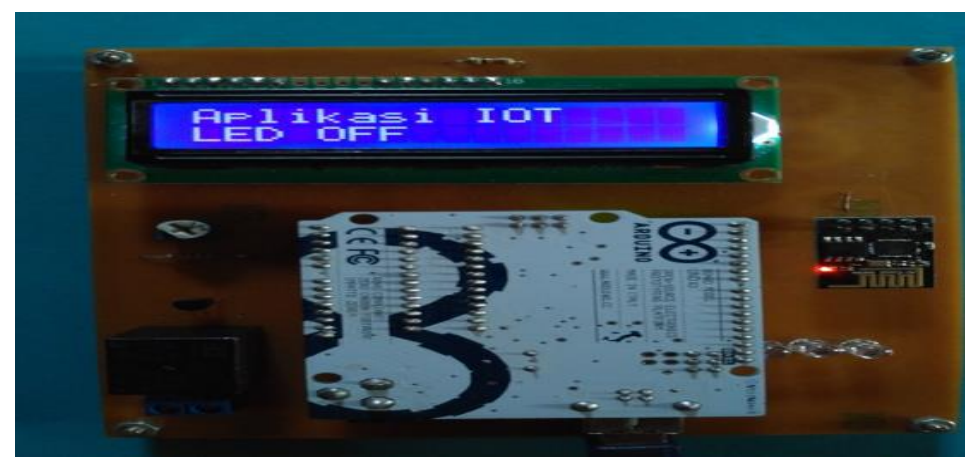

Gambar 7. Uji Fungsi Lampu OFF

Pada Gambar 6 dan Gambar 7 merupakan pengujian hasil dari kendali lampu dengan menggunakan konsep IoT, dapat disimpulkan bahwa lampu dalam keadaan mati dikarenakan grafik pada web menampilkan angka lebih dari nilai 30 lux, nilai tersebut didapat kan dari intensitas kecerahan cahaya yang ditangkap oleh sensor cahaya.

\subsection{Uji Fungsi Lampu ON}

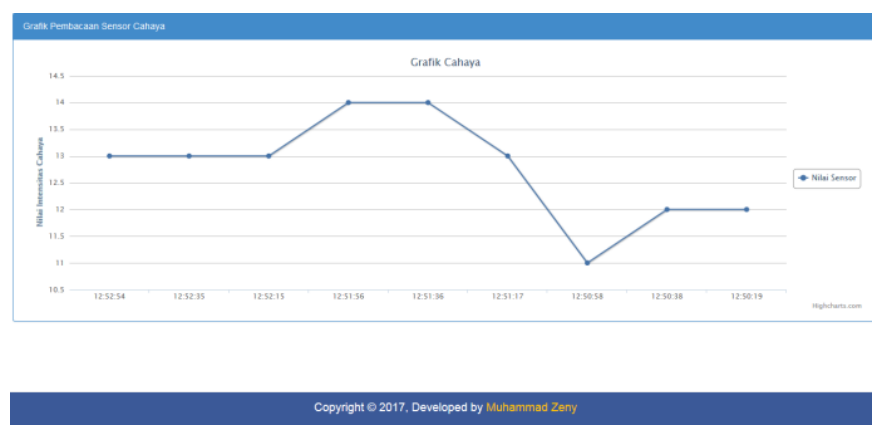

Gambar 8. Uji Fungsi Lampu ON 


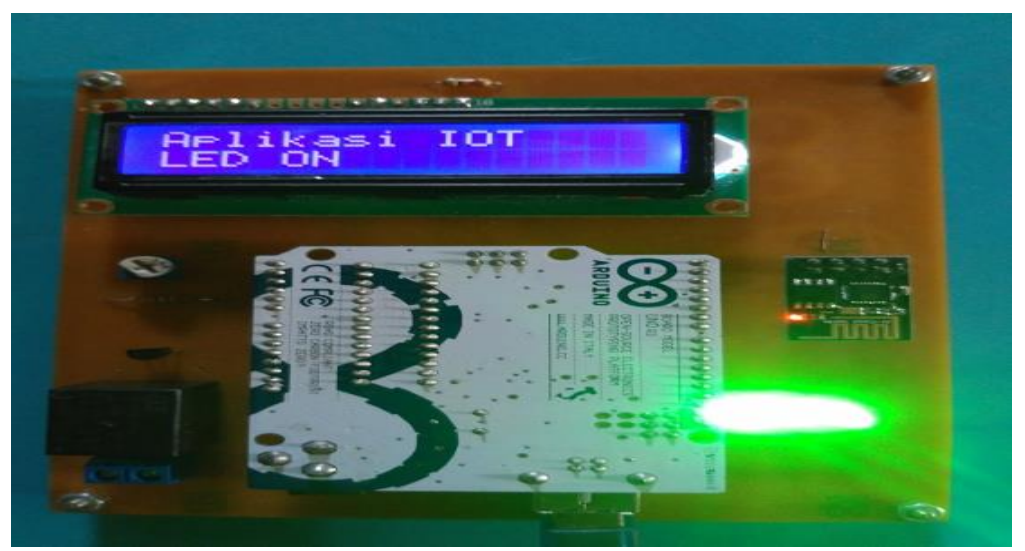

Gambar 9. Uji Fungsi Lampu ON

Pada Gambar 8 dan Gambar 9 merupakan pengujian hasil dari kendali lampu dengan menggunakan konsep IoT, dapat disimpulkan bahwa lampu dalam keadaan hidup dikarenakan grafik pada web menampilkan angka kurang dari nilai 30 lux, nilai tersebut didapat kan dari intensitas kecerahan cahaya yang ditangkap oleh sensor cahaya.

\subsection{Analisi Hasil}

Pengujian pertama adalah pengujian dengan ketahanan Esp, Esp sendiri merupakan modul wifi yang berperan sebagai media komunikasi antara perangkat satu dengan yang lain dengan bertujuan untuk mengirimkan suatu data. Selain itu Esp sebagai modul wifi mempunyai kekurangan, diantaranya adalah mudah terbakarnya modul Esp jika terlalu lama digunakan. Oleh karena itu, pengujian pertama merupakan ketahanan Esp pada konsep IoT, didapatkan kesimpulanya dengan 30 menit bertahan.

Pengujian kedua merupakan nilai hasil atau nilai lux yang dihasilkan oleh sensor cahaya. Nilai yang dihasilkan tersimpan pada database $M y S Q L$. Hasil dari pengujian ini menunjukan bahwa nilai yang dihasilkan tersimpan di database dan web service sebagai pengendali dari eksekusi lampu, dengan memberikan nilai minimum dan maksimum nilai 30 lux.

Pengujian ketiga merupakan kegagalan pada sistem kendali lampu dengan konsep IoT, kegagalan tersebut didapatkan ketika sistem XAMPP yaitu Server Apache dan MySQL dinonaktifkan, sehingga nilai yang dihasilkan sensor tidak dapat terkirim dan sebaliknya Lampu LED tidak bias menerima data yang dihasilkan, Hasil dari pengujian ini menunjukan kegagalan pada sistem bahwa dinonaktifkan sistem, kendali lampu dengan konsep IoT tidak akan berjalan sesuai dengan yang diharapkan.

\section{Penutup}

\subsection{Kesimpulan}

Dari hasil pengujian yang dilakukan dalam penelitian ini dapat disimpulkan bahwa :

1. Penerapan Internet of Things yang diterapkan pada kendali lampu, hidup dan matinya lampu berjalan secara otomatis, sehingga manusia hanya berperan sebagai pengatur dan pemantau berkerjannya alat.

2. Sistem IoT pada kendali lampu tidak akan berjalan apabila XAMPP yaitu Server Apache dan MySQL dalam kondisi mati.

\subsection{Saran}

Untuk mengindari kegagalan pada sistem yang diterapkan pada kendali lampu, diharapkan langkah pertama yang harus dilakukan adalah mengaktifkan kedua sistem yang terdapat pada $X A M P P$ yaitu mengaktifkan server Apache dan MySQL. Supaya Konsep IoT yang diterapkan pada kendali lamu tetap berjalan dengan lancar. 


\section{Daftar Pustaka}

[1] Djuandi, Feri., 2011. Pengenalan Arduino. Jakarta: Elexmedia.

[2] Edi, Kurniawan., 2013. Sistem Penerangan Rumah Otomatis Dengan Sensor Cahaya Berbasis Mikrokontroler. Jurnal Coding Sistem Komputer Universitas Tanjungpura. Vol 1, No. 2, Maret 2013.

[3] Erlina, Dayanti., 2013. Sistem Pengendali Ruangan Secara Otomatis Menggunakan PC Berbasis Mikrokontroler Arduino Uno. Jurnal STMIK. Vol 10, No. 2, Desember 2013.

[4] Hafiddudin., 2015. Perancangan dan Realisasi Alat Pengukur Intentitas Cahaya. Jurnal ELKOMIKA. Vol 3, No. 2, Juli-Desember 2015.

[5] Heri Ardrianto, Aan Darmawan., 2014. Arduino Belajar Cepat dan Pemograman. Jakarta. Informatika

[6] Joni, I Made, Budi Raharjo., 2011. Pemrograman $C$ dan Implementasinya. Bandung. Informatika

[7] Kadir, Abdul., 2015. From Zero to a Pro Arduino. Yogyakarta: Andi

[8] Kristanto, Andi., 2003. Jaringan Komputer. Yogyakarta: Graha Ilmu.

[9] Sumenge., 2014. Perancangan Kendali Lampu Berbasis Android. Jurnal Teknik Elektro dan Komputer. Vol 3, No. 2, April 2014.

[10] Sutono., 2010. Perancangan Sistem Aplikasi Otomatisasi Lampu Penerangan Menggunakan Sensor Gerak Dan Sensor Cahaya Berbasis Arduino Uno. Jurnal UNIKOM. Vol 12, No. 2, Januari 2015.1

[11] Wirdasari, Dian., 2010. Membuat Program Dengan Menggunakan Bahasa C. Jurnal SAINTIKOM. Vol 8, No. 1, Januari 2010. 